Wilfrid Laurier University

Scholars Commons @ Laurier

Sociology Faculty Publications

Sociology

2010

\title{
The Portrayal of Complementary and Alternative Medicine in Mass Print Magazines Since 1980
}

Juanne Nancarrow Clarke

Wilfrid Laurier University, jclarke@wlu.ca

Amy Romagnoli

Wilfrid Laurier University

Cristal Sargent

Wilfrid Laurier University

Gudrun van Amerom

Wilfrid Laurier University, vanx4260@wlu.ca

Follow this and additional works at: https://scholars.wlu.ca/soci_faculty

\section{Recommended Citation}

Clarke, Juanne Nancarrow; Romagnoli, Amy; Sargent, Cristal; and van Amerom, Gudrun, "The Portrayal of Complementary and Alternative Medicine in Mass Print Magazines Since 1980" (2010). Sociology Faculty Publications. 3.

https://scholars.wlu.ca/soci_faculty/3

This Article is brought to you for free and open access by the Sociology at Scholars Commons @ Laurier. It has been accepted for inclusion in Sociology Faculty Publications by an authorized administrator of Scholars Commons@Laurier. For more information, please contact scholarscommons@wlu.ca. 


\title{
The Portrayal of Complementary and Alternative Medicine in Mass Print Magazines Since 1980
}

\author{
Juanne Clarke, Ph.D., Amy Romagnoli, M.A., Cristal Sargent, B.A., and Gudrun van Amerom, B.A.
}

\begin{abstract}
Objectives: The objectives of this study were to examine and describe the portrayal of complementary and alternative medicine (CAM) in mass print media magazines.

Design: The sample included all 37 articles found in magazines with circulation rates of greater than 1 million published in the United States and Canada from 1980 to 2005. The analysis was quantitative and qualitative and included investigation of both manifest and latent magazine story messages.

Results: Manifest analysis noted that CAM was largely represented as a treatment for a patient with a medically diagnosed illness or specific symptoms. Discussions used biomedical terms such as patient rather than consumer and disease rather than wellness. Latent analysis revealed three themes: (1) CAMs were described as good but not good enough; (2) individualism and consumerism were venerated; and (3) questions of costs were raised in the context of confusion and ambivalence.
\end{abstract}

\section{Introduction}

C ONVEnTIONAL MEDicine has been both the dominant form of health care in the Western world and growing in importance through the process of medicalization ${ }^{1}$ since the Flexner Report in $1910^{2}$ and the development of antibiotic and antipsychotic drugs in the early part of the 20th century. ${ }^{3}$ The process of medicalization has been both entrenched and accelerated up since the 1970s. ${ }^{4}$ Conrad argues that the essence of medicalization is definitional power or "defining a problem in medical terms, usually as an illness or disorder or using a medical intervention to treat it." 4 The supremacy of the medical model is justified by its (supposed) reliance on positivistic science. ${ }^{3,5}$

At the same time, however, there is no doubt that the use of complementary and alternative medicines (CAM) has increased in the United States, the United Kingdom and Canada and elsewhere in the Western world. ${ }^{6}$ In 1993, Eisenberg and his colleagues ${ }^{7}$ reported on the extent of the use of unconventional medicine in a national sample of the U.S. population. Massage, herbs, spirituality, religion, energy healing, folk remedies, megavitamin therapy, commercial weight loss programs, lifestyle diets, and support groups were among the various therapies included in the national utilization survey. Thirty-four percent $(34 \%)$ of their respondents had used one or more unconventional therapies. In 1998, Eisenberg and colleagues published the results of a national follow-up survey and found that the utilization rate had grown to $42.1 \%{ }^{8}$ Eisenberg and colleagues ${ }^{8}$ estimated that there were 629 million visits to CAM providers in 1997 at an out-of-pocket cost of 27 billion dollars in the United States. The frequency of CAM practitioner visiting was higher than that of conventional medicine, and the out-ofpocket costs were about equal for the two types of health care. ${ }^{9}$ More recently, the National Center for Health Statistics found that $36 \%$ of Americans used some form of CAM, but when prayer and megavitamin therapy were included, $62 \%$ were considered to be CAM users. ${ }^{9}$ Notably, however, the majority of people did not "confess" to their allopathic physicians about their CAM utilization. ${ }^{9}$

The Canadian Community Health Survey indicated, too, that the frequency of CAM use (professional services only) among Canadians is significant and has risen. During the 1994-1995 time period, 15\% of Canadians over the age of 12 used alternative medical treatment. ${ }^{10}$ The rate rose to $20 \%$ of Canadians in $2003 .^{10}$ The rates of CAM utilization have been estimated to be between $10 \%^{11}$ and $20 \%{ }^{12}$ in the United Kingdom.

It is thus clear that a sizable minority of people in each of these countries uses some type of CAM. Determining what to call CAM is, however, challenging; "alternative, complementary, holistic, unorthodox, unconventional, non-scientific, and marginal" are some of the options. ${ }^{13}$ However defined, CAMs, their utilization, and deciding what forms of "treatment" to include in these statistical estimates are problematic. ${ }^{14}$ There are areas of incommensurability among

Department of Sociology, Wilfrid Laurier University, Waterloo, Ontario, Canada. 
different CAMs including (1) the lack of shared principles, (2) disparate theories and goals of the various CAM practices, (3) the (sometimes) inclusion of CAM within conventional medicine, and (4) porous and changing boundaries between different types of CAM. ${ }^{15}$ There have been a number of typologies for distinguishing among CAMs. One, by Goldstein, ${ }^{16}$ suggests that the following core beliefs give CAM its coherence; (1) holism (e.g., mind-body unity), (2) vitalism (a life force that promotes healing), (3) an emphasis on spirituality and/or religion (often using secular language such as therapeutic touch), (4) the notion that health is more than the absence of symptoms, (5) the idea that health can only be gained through hard work and is possible even in the presence of disease, and (6) the belief that the healer is also a partner.

Many of the treatments included in the various types of CAM do not require consultation with a professional. Others require consultation with health care providers such as chiropractors, naturopaths, homeopaths, and/or acupuncturists. CAMs vary in cost. Some, such as prayer, are free. Many others, such as commercial weight loss diets, megavitamins, and the services of professional practitioners can be costly. Depending on which CAMs are included, there are different levels of utilization. Utilization rates of the disparate types of CAM are undoubtedly associated with different social class and other sociodemographic variables. Many studies have found a positive relationship between education level, income, and CAM use. ${ }^{10,17}$ In addition, women, whites, and more highly educated and younger people are more frequent users of CAM. ${ }^{17-19}$ Spiritual healing appears to be associated with nonwhites. ${ }^{19}$

CAM utilization rates appear to be increased by the presence of a serious chronic or life-threatening illness. ${ }^{20-22}$ For instance, studies have found utilization rates of between 1 in 10 and 2 in 3 in cases where people have been diagnosed with cancer. ${ }^{22}$ Whether or not disappointment with conventional medicine plays a significant role in CAM use is empirically unclear, ${ }^{23,24}$ nor has the argument that people choose CAM to assert personal control been widely supported. ${ }^{19}$ Social networks appear to have an impact on CAM choice. $^{13}$

In Western societies, there is evidence of the sustainability of the medicalization thesis at least in the near future. ${ }^{3,4,25,26}$ At the same time, strong arguments have been made for the increasing use of CAM and for the integration of CAMs into mainstream medical practice. ${ }^{27}$ Critical assertiveness among health care consumers and a greater willingness to question the safety and efficacy of conventional or allopathic medicine both play a role in this trend..$^{28}$ Moreover, various CAMs are presently being included in medical school curricula and used by conventional doctors, ${ }^{3,26}$ as adjuncts to and integrated into conventional treatments. There are a number of new peer-reviewed scientific journals focusing on CAMs. ${ }^{28}$ Clearly there is evidence of change in the areas of CAM and conventional medicine.

\section{Media Analysis}

One of the possible contributions to CAM understandings, use, and its increase may be the mass media. Mass media often reflect and reinforce a system "of values, beliefs and morality that supports the established order and the class interests that dominate it." 29
Health and social policies related to diagnosis, treatment, prevention, health promotion, research directions, and supportive services, among other things, are related to media portrayal. ${ }^{29}$ The research will examine the framing of stories regarding CAM where framing is thought to establish the boundaries regarding what and how topics will be discussed by selecting some "aspects of a perceived reality." ${ }^{\prime 30}$ More simply, frames are "like the border around a picture that separates it from the wall." ${ }^{30}$

\section{Mass Media and the Portrayal of CAM}

Available research is scant. There were only three articles found on the portrayal of CAM in the mass media. Doel and Segrott ${ }^{31}$ have examined issues in regard to the portrayal of CAM in health and lifestyle magazines designed specifically for women. ${ }^{31}$ They argue that the focus in these magazines is on the ways in which CAM may be used as a part of women's quest for "well-being" and as a reflection of women taking personal responsibility as increasingly "smart" and discerning consumers. They also argue that specific diseases have been replaced with a generic "dis-ease" with life, so that the reasons to use CAM have no limits. ${ }^{31}$

Kirkman $^{32}$ undertook an interpretive content analysis of CAM, in New Zealand women's magazines. She found that both conventional medicine and CAMs were presented in magazines with approximately equal frequency and found a blurring of boundaries between orthodox practitioners and alternative therapists. $^{32}$

The purpose of this research is to analyze and describe the portrayal of CAM in popular mass media magazines with circulation rates of greater than 1 million. Magazines used for this article include Better Homes and Gardens*, Business Week, Glamour*, Good Housekeeping*, Mademoiselle*, Men's Health, McCall's*, Maclean's, Newsweek, Prevention, Redbook* Time, and U.S. News and World Report. Six (6) of these magazines are marked with an $\left(^{*}\right)$ to indicate that their audiences are largely female. The others are directed to general audiences.

\section{Methods}

\section{Sample/population}

This study was based on all full-text articles (without graphics) on the topic of CAM in the English language magazines with circulation rates of more than 1 million and available in Canada and published in Canada or the United States from 1980 to 2005. It also included Maclean's magazine because it is the highest circulating national newsmagazine available in Canada even though its circulation figures do not reach 1 million. The Reader's Guide to Periodicals Index was used to locate all articles indexed under complementary and/or alternative medicine and any internal links mentioned. These included acupuncture, chiropractics, naturopathy, holistic medicine, home remedies, alternative medicine, and homeopathy. These years were selected in order to provide enough data over a long enough period of time to avoid the bias of the selection of 1 year only when a particular event, such as the announcement of new "natural" treatment product might occur. The time period was also selected in order to accrue a sufficient number of articles for analysis. It must be noted that meanings may have changed and over time in an imperceptible manner and that we may have inadvertently excluded 
some articles because of our specific search strategy. For example, searching for articles on natural medicine may have resulted in a different series of stories. It is important to note that there were many other articles on CAM in mass magazines but they were excluded because the circulation rates of these magazines did not reach 1 million.

\section{Data analysis}

Initially, all articles were read to categorize them for manifest, surface, or intended content, and as focusing on one type of CAM or another, mentioning a disease or not, referring to users as patients or consumers, associating CAM utilization with disease or wellness, mentioning celebrity, social class, or gender among other things (a full copy of the manifest coding categories is available from the authors). ${ }^{33,34}$ Subsequently, for the latent, subsurface, or unintended analysis, all articles were read and summarized as to their framing of CAM, topics of discussion, and types of attitude toward CAM. ${ }^{35}$

With qualitative data analysis concerns such as reliability and validity become credibility, transferability, dependability, and confirmability. ${ }^{36}$ These criteria were attended to in the data analysis.

\section{Results}

\section{Manifest analysis}

There is a growth in the numbers of articles over time. There were 9 articles found on the topic between 1985 and 1994 and 28 found between 1995 and 2004 under the terms CAM.

Table 1 indicates the types of illnesses and diseases discussed in the CAM articles and the frequency with which they appeared. CAM was usually discussed in the context of specific symptoms and diseases.

Table 2 indicates how often articles used the terms "patient" and "consumer." CAM is referred to in the context of a biomedical model through the deployment of the term "patient," with more than three times the frequency as the term "consumer."

Table 3 indicates the gender to which the articles were directed. In this population of articles, gender neutrality prevails. Eight-one percent $(81 \%)$ of the articles were directed at either both men and women or neither men nor women.

Table 4 indicates how often articles were focused on disease, wellness, or both. Again, most articles focused on disease or disease in addition to wellness. Only $11 \%$ described CAM solely in respect to wellness, prevention, or holism.

A very small minority of articles described individuals and among these, there were very few references to income or occupation or other indices of social class or status.

\section{Latent analysis}

Theme 1: Medicalization persists. The first significant theme in the latent analysis is the persistence of a biomedical perspective in articles about CAM. Six aspects of this follow.

1. Good but not good enough

An underlying and consistent theme in many articles that discuss CAM is that it is good, but not good enough. That is, rather than being an alternative, CAM is best thought of as complementing and being used in conjunction with con-
Table 1. Conditions Treatable by Complementary and Alternative Medicine

Treatment for: $\quad \begin{gathered}\text { No. of times } \\ \text { appeared in article }\end{gathered}$

Back/joint muscle pain 10

Headaches/migraines 8

Bites/stings/burns

Arthritis

Heart disease

Nausea

Premenstrual syndrome/menopause

Respiratory (asthma, chronic lung disease)

Cancer

Indigestion

Substance abuse

Congestion

Earaches

Irritable bowel syndrome

Skin conditions

Tooth/mouth

Acquired immune deficiency syndrome

Allergies

Colic

Depression

Diabetes

Erectile dysfunction

Insomnia

Overeating/weight loss

Sore throats (laryngitis)

Carpel tunnel

Constipation

Cradle cap

Diarrhea

Hemorrhoids

High blood pressure

High cholesterol

Malarial conditions

Multiple sclerosis

Parkinson disease

Reynaud syndrome

Scurvy

Stroke

ventional medicine. Following are a few quotations taken from a variety of articles and illustrating this theme: (1) "Naturopathic doctors (NDs) can provide add-on treatment if you're being seen by an MD for a chronic health condition such as diabetes or heart disease" $(10 ; 48)$; $^{*}$ and $(2)$ "There is one point on which doctors and reputable alternative therapists agree: Natural therapies should be used in conjunction with, but not instead of, conventional medicine" $(63 ; 38)$.

\section{Potentially dangerous}

Readers are frequently warned to beware of CAM. Potential users are advised of its putative dangers. "Skeptics worry that the new permissiveness could hurt consumers by encouraging useless or even dangerous medical practices" (32;

*Numbers after quotations in the data analysis in this section all refer to magazine and page numbers from the data bibliography available from the first author. 
Table 2. Use of Terms: Patient Versus Consumer

\begin{tabular}{lcc}
\hline Audience & $\begin{array}{c}\text { No. of articles } \\
\text { that use terminology }\end{array}$ & $\begin{array}{c}\text { Percentage } \\
\text { of total (\%) }\end{array}$ \\
\hline Consumer & 4 & $24 \%$ \\
Patient & 13 & $76 \%$ \\
Total & 17 & $100 \%$ \\
\hline
\end{tabular}

56). A frequently expressed fear was that CAM would become the primary source of health care: "Conventional wisdom holds that the only real danger of alternative medicine is that it might keep you from seeing your primary physician, increasing the risk that a serious illness will go undiagnosed" $(18 ; 62)$. "Stick with mainstream medicine for any condition that's life threatening and any ailment easily controlled with well-tailored medication (such as diabetes)" (18; 62).

\section{Lacking evidence}

CAM is said to lack research and empirically based evidence regarding safety and efficacy. One doctor describes the research that has been done on CAM therapies as "hokum" $(18 ; 60)$. CAMs are described as unsafe and ineffective because they "defy basic laws of chemistry and physics or run counter to commonly held notions of anatomy" $(48 ; 56)$.

4. Should be used along with conventional medical care CAM portrayal also includes a notion that it should only be used in addition to conventional medicine. As one article states, "We should recognize that modern medicine or traditional home remedies may be valid at different times for different reasons, and there will be times when both can work together toward the goal of healing" $(57 ; 67)$. For example, one article explains that, "in some cases, the best method is a combination of East meets West" $(48 ; 66)$. In another article the universe is described as "one big medicine cabinet" $(51 ; 77)$. However, U.S. medicine was still considered the best. People are advised that "the next time you come down with something that doesn't require surgery-we'd never leave the States for that-consult your atlas" $(51 ; 77)$.

5. Against the advice of conventional doctors

The popularity of CAM is said to have grown despite general resistance from allopathic practitioners. In other words, "in the spirit of if-you-can't-lick-'em-join-'em, scores of doctors and hospitals across the country are exchanging their traditional adversarial position for one of cooperation" (76; 69). Few doctors were presented as enthusiastic about this integration. One exception follows: "Today, in large part thanks to Harvard-educated Andrew Weil, M.D., 58, and a movement he helped forge, integrative medicine-an amalgam of drugs and surgery, Western medicine, and alterna-

Table 3. Mention of Gender of "Patient" in Article

\begin{tabular}{lcc}
\hline Gender & No. of articles & Percentage of total \\
\hline Female & 3 & $8 \%$ \\
Male & 4 & $11 \%$ \\
Both/neutral & 30 & $81 \%$ \\
Total & 37 & $100 \%$ \\
\hline
\end{tabular}

Table 4. Focus of Article: Disease Versus Wellness

\begin{tabular}{lcc}
\hline Focus & No. of articles & Percentage of total \\
\hline Disease & 20 & $54 \%$ \\
Wellness & 4 & $11 \%$ \\
Both & 13 & $35 \%$ \\
Total & 37 & $100 \%$ \\
\hline
\end{tabular}

tive treatments from acupuncture to homeopathy-is one of the fastest growing health disciplines" $(13 ; 156)$.

6. CAM is to be used after conventional medicine has been tried

Individuals are encouraged to treat themselves with CAM only when conventional medicine does not work. For example, after being diagnosed as human immunodeficiency virus-positive, one man began "investigating alternative therapies almost immediately" $(63 ; 35)$. "Now 48, Mountford credits a range of alternative treatments, from nutritional counseling to acupuncture and herbs, which helped to alleviate the side-effects of AIDS drugs and to control his pain" $(63 ; 35)$. In another example, after Rosario Farro discovers that she has breast cancer for the second time in 8 years, she refuses to undergo radiation and chemotherapy "convinced that they would do more harm than good" $(63 ; 37)$ and decides to take "massive doses of vitamins and minerals under the supervision of a physician interested in holistic health" $(63 ; 37)$.

Theme 2: Individualism and consumerism are venerated. The second major theme is that CAM utilization reflects individual choices made by patients or consumers who are described as free and able to determine what they themselves think is best. In this context, individual choice may be glorified and the personal characteristics of CAM users presented as particularly admirable.

\section{Holism and individualism}

One of the chief appeals in the positive portrayal of CAM is the idea that patients/consumers are not just bodies because "their goals are to prevent illness, treat the whole person, and help the body heal itself via natural means" (10; 48). This view is said to acknowledge the uniqueness of each individual. "Homeopaths often individualize treatment, matching remedies to a patient's particular pattern of symptoms" (48; 56).

\section{Individuals should have free choice}

The individual is described as an active consumer with "more health care options" $(63 ; 34)$ to choose from. Many articles contained guides to educate the modern health consumer. One article begins: "Ready for the plunge? This guide will give you an informed insider's perspective" $(67 ; 29)$.

3. Health is the responsibility of the individual

CAM articles also accentuate that the individual is responsible for a healthy life and lifestyle and for choosing CAM to promote these ideals. For example, "a cornerstone of care at the Marino clinic is that patients must actively work to help themselves, including altering diet, quitting smoking and getting more exercise" $(46 ; 135)$. 
Theme 3: Costs. There is little discussion of the financial aspects of CAM. In some articles, allopathic medicine was described as the superior form of medicine. CAM was thus reserved for the rich because CAM was usually not covered by health care insurance but was an out-of-pocket expense. In other articles, CAM was described as providing a cheaper alternative for (uninsured) individuals from lower socio-economic positions. It was noted that some insurance companies have begun to cover CAM in an effort to cut costs, "Intrigued by the possibility that patients might find real relief with cheaper therapies, insurers are beginning to cover certain alternatives" (56; 1 of 2).

\section{People pay for CAMs themselves}

Despite the move toward some insurance coverage, most people are portrayed as paying for CAM. Thus, CAM is not a choice for individuals from all socio-economic positions. The cost of CAM is noted in the following example, "Be prepared to pay your bill" $(80 ; 64)$. Despite the cost, "these days, middle-of the road Americans like Trembour are turning in increasing numbers to such unconventional approaches when they feel sick" $(65 ; 106)$.

\section{Profit motive of CAM sometimes questioned}

Several articles included a critique of the profit orientation of CAM as compared to conventional medicine. The idea of a competition between conventional and CAM medications is sometimes encouraged. "Conventional medicine is looking more closely at the competition" $(48 ; 56)$ and critiqued. "The bottom line is that the manufacturers of homeopathic remedies are raking in hundred of millions of dollars a year for products that may not be more effective than ordinary tap water and are probably not as pure" (70; 1 of 2).

\section{Discussion}

The first point to be emphasized is that there were more than three times as many articles on various CAMs in the second decade analyzed as there were in the first (1985-1994, 1995-2004). This growth in the frequency of articles reflects the growing utilization rates for CAM. However, ongoing ambivalence was demonstrated by the fact that CAM was usually contextualized by perspectives such as disease (an idea pertinent to the biomedical model) and patients rather than wellness and consumers (relevant to CAM). Both men and women tended to be addressed in these stories.

In the latent analysis, CAM is presented as good but not as good as conventional medicine. CAM was sometimes described as devoid of scientific value, as potentially dangerous unless used under the jurisdiction of an allopathic practitioner or for trivial health concerns. Those who choose CAM are described as differing from others because they are especially concerned about their health and well-being and as subscribing to the belief that CAM is uniquely designed for the whole of the body, mind, and spirit. Individuals are portrayed as having the right to choose a healthy lifestyle, which is said to include the use of CAM when this is desired, when faced with a serious illness, or when conventional medicine does not work.

There is little mention of the social or economic constraints involved in using CAM. However, what was included was contradictory. Sometimes conventional medicine was de- scribed as too expensive. Yet, for those covered by insurance it was CAM that was costly because CAM was seldom covered. In addition, there was some discussion about the possibility that CAM providers and companies manufacturing treatments were financially motivated rather than altruistic, as conventional medicine was said to be.

These findings underscore the continued valorization of medicalization as the defining perspective regarding the good and the bad in health care. CAM is described as holistic care not because it takes into consideration the individual in the context of family, friends, neighborhood, work, church, or any other aspect of social life but because it emphasizes the glorification of the individual who is seen not only as a biological organism, as is the tendency of conventional allopathic medicine, but as a complex whole, composed of body-mind-spirit.

This individualizing strategy may be particularly important in a situation in which medicalization is, as Conrad ${ }^{4}$ argues, being advanced less as a result of the interests of the medical profession, as it was in the past, and more in the interests of free enterprise and capitalism, particularly the pharmaceutical and biotechnology industries. ${ }^{25}$ The underscoring of the image of the individual as an active consumer and the appeal to freedom of choice represent an indirect way of buttressing capitalism and both conventional medicine and CAM. Individualizing is also reflective of the variety of rights movements, including other health and fitness movements.

Goldstein suggests that there are significant economic forces behind the growth of CAM. ${ }^{25}$ Among the major economic beneficiaries on the global stage are medical associations, the pharmaceutical industry, Health Maintenance Organizations, insurance companies, media conglomerates, and Internet providers as well as the interests of political, bureaucratic and new social movements' actors and interests. ${ }^{25}$ These organizations have all been growing along with the expansion in CAM and certainly stand to gain as CAM becomes more widely accepted.

\section{Conclusions}

This media analysis suggests that there is a sort of battle going on in the public sphere of media portrayal. On the one hand is the portrayed assumption that allopathic medical care is itself the "gold standard" for thinking about bodies and health. However, the biomedical model maintains a shaky position of dominance. On the other hand, there is a competing idea of the benefits of CAM for the new independent and "whole" person of the future. Further research on this topic should compare media in different jurisdictions and follow the changes in media representation as the prevalence rates for CAM utilization change, and, most likely, increase.

\section{Acknowledgments}

We would like to gratefully acknowledge the support of the Social Sciences and Humanities Research Council for funding for this project.

\section{Disclosure Statement}

No competing financial interests exist. 


\section{References}

1. Zola I. Medicine as an instrument of social control. Sociol Rev 1972;20:487-504.

2. Flexner A. Medical Education in the United States and Canada. New York: The Carnegie Foundation for the Advancement of Teaching, 1910.

3. Clarke JN. Health, Illness and Medicine in Canada. Toronto: Oxford University Press, 2004.

4. Conrad P. The shifting engines of medicalization. J Health Social Behav 2005;46:3-14.

5. Freund PES, McGuire MB, Podhurst LS. Health, Illness and the Social Body. 3rd ed. Upper Saddle River, NJ: Prentice Hall, 2003.

6. Fisher P, Ward A. Complementary medicine in Europe. BMJ 1994;309-310.

7. Eisenberg DM, Kessler RC, Foster C, et al. Unconventional medicine in the United States: Prevalence, costs, and patterns of use. NEJM 1993;328:246-252.

8. Eisenberg DM, Davis RB, Ettner SL, et al. Trends in alternative medicine use in the United States, 1990-1997: Results of a follow-up national survey. JAMA 1998;280:1569-1575.

9. NCCAM. February 20, 2009. The National Centre for Complementary and Alternative Health. Online document at: from http://nccam.nih.gov/ Accessed May 9, 2006.

10. Sibbald B. News @ a glance. Can Med Assoc J 2005;172:170.

11. Ernst E. The role of complementary and alternative medicine. BMJ 2000;321:1133-1135.

12. Coleman $\mathrm{P}$, Thomas K. Use of complementary or alternative medicine in a general population in Great Britain: Results from the National Omnibus survey. J Public Health 2004;26: 152-157.

13. Kelner M, Wellman B, eds, Pescolido B, Saks M, associate eds. Complementary and Alternative Medicine: Challenge and Change. Singapore: Harwood Academic Publishers, 2000.

14. Fennell D, Liberato A, Zsembik B. Complement Ther Med 2009;17:71-77.

15. Kaptchuk TJ, Eisenberg DM. Varieties of healing: 2: A taxonomy of unconventional healing practices. Ann Intern Med 2001;135:196-204.

16. Goldstein MS. The emerging socioeconomic and political support for alternative medicine in the United States. Ann Am Acad Political Social Sci 2002;583:63.

17. McFarland BH, Bigelow DA, Zani B, et al. Complementary and alternative medicine use in Canada and the United States. Am J Public Health 2002;92:1616-1618.

18. Verheij $\mathrm{R}$, de Bakker D, Groenewegen P. Is there a geography of alternative medical treatment in The Netherlands? Health Place 1999;5:83-97.

19. Astin J. The characteristics of CAM users: A complex picture. In: Kelner M, Wellman B, Pescosolido B, Saks M, eds. Complementary and Alternative Medicine: Challenge and Change. Amsterdam: Hardwood, 2000:101-114.

20. Adams J, Sibbritt D, Young AF. Naturopathy/herbalism consultations by mid-aged Australian women who have cancer. Eur J Cancer Care 2005;14:443-447.

21. Adler SR. Complementary and alternative medicine use among women with breast cancer. Med Anthropol Q 1999; $13: 214-222$.
22. Humpel N, Jones SC. Development of a comprehensive questionnaire of complementary and alternative medicine use among cancer patients and survivors. Complement Health Practice Rev 2005;10:163-174.

23. Sharma U. Medical pluralism and the future of CAM. In: Kelner M, Wellman B, Pescosolido B, Saks M, eds. Complementary and Alternative Medicine: Challenge and Change. Amsterdam: Hardwood, 2000:211-222.

24. Furnham A, Vincent C. Reasons for Using CAM. In: Kelner M, Wellman B, eds., Pescolido B, Saks M, associate eds. Complementary and Alternative Medicine: Challenge and Change. Singapore: Harwood Academic Publishers, 2000: 61-78.

25. Williams SJ, Calnan M. The "limits" of medicalization?: Modern medicine and the lay populace in "late" modernity. Social Sci Med 1996;42:1609-1620.

26. Clarke AE, Shim JK, Mamo L, Fosket JR, Fishman JR. Biomedicalization: Technoscientific transformations of health, illness, and U.S. biomedicine. Am Sociol Rev 2003;32:12-21.

27. Ernst E. Integrated Medicine: The best of both worlds or the worst for our patients? Complement Ther Med 2008;1:179 180.

28. NCCAM. NCCAM's International Centers for Research on CAM (ICRCs). January 9, 2009. Online document at: http:// nccam.nih.gov/research/oihr/icrc-description.htm Accessed October 26, 2009.

29. Waitzkin H. A critical theory of medical discourse: Ideology social control and the processing of social context in medical encounters. J Health Social Behav 1989;30:220-239.

30. Entman RM. Framing: Toward clarification of a fractured paradigm. J Communication 1991;43:51-58.

31. Doel MA, Segrott J. Self, health, and gender: Complementary and alternative medicine in British mass media. Gender Place Culture 2003;10:131-144.

32. Kirkman A. Productive readings: The portrayal of health "experts" in women's magazines. Qual Health Res 2001; 11:751-765.

33. Berg BL. Qualitative Research Methods for the Social Sciences. Boston: Allyn \& Bacon, 1989.

34. Neuman WL. Social Research Methods: Qualitative and Quantitative Approaches (4th ed.). Toronto: Allyn and Bacon, 2000.

35. Gamson WA, Modigiliani A. Media discourse and public opinion on nuclear power: A construction approach. Am Sociol 1989;95:1-37.

36. Jackson W. Methods: Doing Social Research. Toronto: Prentice Hall, 2003.

Address correspondence to: Juanne Clarke, Ph.D.

Department of Sociology

Wilfrid Laurier University 75 University Avenue West Waterloo, Ontario N2L 3C5

Canada

E-mail: jclarke@wlu.ca 